\title{
Hypotriglycedemic Action of Synthetic ACTH
}

\author{
FuKaShi MATSUZAKI, Miki KOMIYAMA AND KaZUo SHIZUME
}

\author{
Department of Endocrinology, Toranomon Hospital, Institute for Adult Disease, \\ Asahi Life Foundation, The 3rd Department of Internal Medicine. \\ Faculty of Medicine, University of Tokyo
}

\section{Synopsis}

The hypotriglycedemic action of ACTH was investigated in the hyperlipemic patients of various diseases. This effect was apparent within $30 \mathrm{~min}$ after intravenous injection of the hormone and lasted up to $96 \mathrm{hr}$ when it was administered intramuscularly. ACTH had no effect on the serum cholesterol or phospholipid concentration. As possible causes of this effect of ACTH, fatty acids mobilization and lipoprotein lipase activation were excluded and hepatic involvement was suggested.

In one hypopituitary patient associated with hypertriglycedemia of carbohydrate induced type (Frederickson, Type IV), it was incidentally observed that synthetic adrenocorticotropic hormone $\left(\beta^{1-24} \mathrm{ACTH}\right)$ markedly decreased the plasma triglyceride (TG) concentration. In the literature, Friedman, et al. have already reported the TG lowering action of ACTH in hypertriglycedemic patients (Friedman et al., 1964; Friedman et al., 1967). However, such an effect of ACTH has not been reported elsewhere and in their report the effect of ACTH was noticed only in the moderately hypertriglycedemic patients. Since this extra-adrenal action of ACTH has not widely been recognized and since its $\mathrm{TG}$ lowering action observed in our hypopituitary patient was so marked and rapid, we have further studied the effect of ACTH on serum TG concentration as well as on serum cholesterol and phospholipid concentration in 12 patients with various disorders.

Received for publication October 6, 1971.

\section{Materials and Methods}

Patients studied were chosen among those who visited the Department of Endocrinology, Toranomon Hospital. They consisted of 4 diabetics (T. I., K. T 2 , K. S., S. E.), 4 hypopituitary patients postoperative to pituitary tumors (Y. I., N. O., H. A., K. K.) and one patient of acromegaly $\left(K . T_{1}\right.$.), essential hyperlipemia (Frederickson Type II, T. T. and Type IV, Y. S.) and Cushing's syndrome (S. M.). ACTH used in this study was cortrosyn tetracosactide (N. V. Organon), in an amount of $250 \mu \mathrm{g}$ intravenously or $1.0 \mathrm{mg}$ intramuscularly in its long acting depot form (cortrosyn-Z). Blood samplings at 0 and 24, $48 \mathrm{hr}$ after the administration were done in the fasting state before breakfast. Meals were not restricted, so that the 4-and 8-hr samples represented $4 \mathrm{hr}$ after breakfast or lunch, respectively. Serum TG concentration was measured by the Kawade's modification (Kawade, 1962) of Van Handel's method (Van Handel and Zilversmit, 1957), total cholesterol by the modified Zak-Henly method (Zak, 1955; Henly, 1957; Shibata and Kitamura, 1963) and phospholipid by the phenylpyrazolidone method (Yoshida and Igarashi, 1962). Lipoprotein lipase activity was measured 10 minutes after heparin administration $(0.1 \mathrm{U} / \mathrm{kg} \mathrm{BW})$ according to the method of Frederickson et al. (Frederickson et al., 1962) using soybean oil (Intralipid, Apoteksvarucentralen Vitrum $\mathrm{Ab}$, Sweden) as a triglyceride substrate. Serum free fatty acid concentration was measured by the microtitration method by Dole (Dole, 1956). 


\section{Y.I. 18 \& Hypopituitarism}

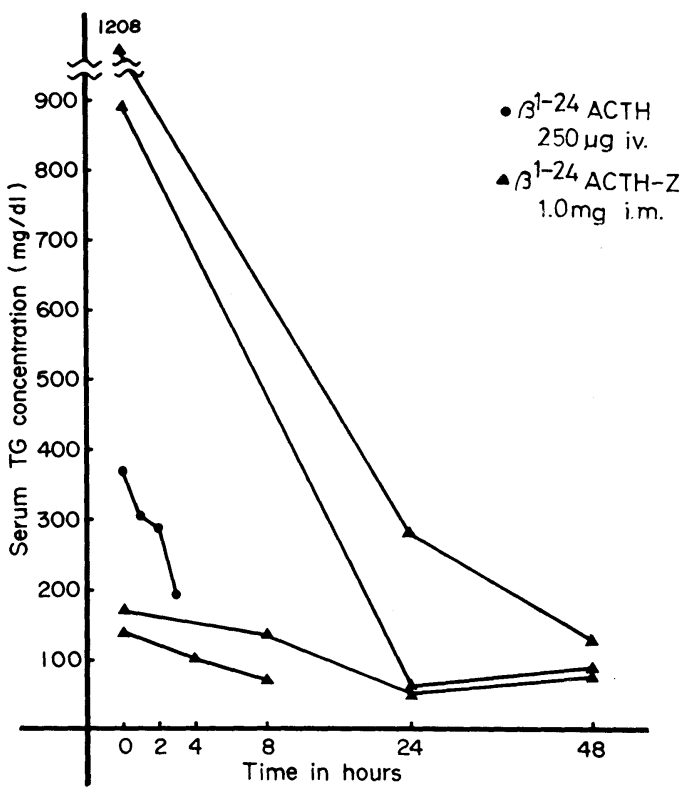

Fig. 1. Change in serum TG concentration (mg/dl) after ACTH administration in a patient Y. I. ACTH was injected either intravenously in an amount of $250 \mu \mathrm{g}$ (circles) or intramuscularly in an amount of $1.0 \mathrm{mg}$ (triangles).

\section{Results}

Effect of ACTH on serum TG concentration

Figure 1 shows the results of ACTH administration either intravenously or intramuscularly to a patient (Y. I.) of carbohydrate induced hyperlipemia. When administered intramuscularly in an amount of $1.0 \mathrm{mg}$, ACTH decreased the serum TG concentration from $1208,890 \mathrm{mg} / \mathrm{d} l$ to $275,80 \mathrm{mg} / \mathrm{d} l$ in 24 $\mathrm{hr}$ and to $130,125 \mathrm{mg} / \mathrm{d} l$ in $48 \mathrm{hr}$, respectively. In another study, ACTH depressed the high TG concentration of $775 \mathrm{mg} / \mathrm{d} l$ to $83 \mathrm{mg} / \mathrm{d} l$ in $24 \mathrm{hr}$ and remained to be less than $150 \mathrm{mg} / \mathrm{d} l$ for no less than $96 \mathrm{hr}$. The effect of ACTH became apparent within $4 \mathrm{hr}$ by this route of administration. When administered intravenously, $250 \mu \mathrm{g}$ of ACTH lowered the serum TG concentration already in $30 \mathrm{~min}$ by nearly $50 \%$. It is not only in this patient that the hypotriglycedemic action of ACTH was observed, but in other hyperlipemic patients of various diseases responded in the same manner. In Table 1 is summarized the result in the patients who responded to the ACTH administration. Besides the patient described above (Y. I.), hyperlipemics of various diseases, namely acromegaly, essential hyperlipemia, diabetes or hypopituitarism, responded to ACTH. In Table 2 are listed those who did not respond to the ACTH administration. Most of the cases are clearly those whose fasting blood TG concentrations were low to begin with. However, 2 cases are included in the table who had high blood TG concentration and did not respond to ACTH. One of them was a patient of Cushing's syndrome associated with diabetes and the other was a diabetic. The blood TG concentration of either case fell within normal

Table 1. Change in serum TG concentration (mg/dl) after ACTH administration (Responders)

\begin{tabular}{ccccccc}
\hline Patien & Diagnosis & 0 & $4 \mathrm{hr}$ & $8 \mathrm{hr}$ & $24 \mathrm{hr}$ & $48 \mathrm{hr}$ \\
\hline Y. I. & Hypopituitarism & 1210 & & & 275 & 130 \\
Y. S. & Essential hyperlipemia & 1100 & & & 409 & 391 \\
K. To. & Acromegaly & 580 & 556 & 481 & 314 & 239 \\
K. Ta. & Diabetes mellitus & 234 & 246 & & 197 & 149 \\
N. O. & Hypopituitarism & 174 & & 159 & 81 & \\
Y. I. & Hypopituitarism & 171 & 192 & 138 & 57 & 80 \\
Y. I. & Hypopituitarism & 141 & 109 & 77 & & \\
H. A. & Hypopituitarism & & 187 & 92 & 82 & 100 \\
\hline
\end{tabular}

$1 \mathrm{mg}$ of synthetic ACTH was injected intramascularly at 0 time. 
Table 2. Change in serum TG concentration (mg/dl) after ACTH administration (Non-responders)

\begin{tabular}{clrrrrr}
\hline \hline Patient & \multicolumn{1}{c}{ Deagnosis } & \multicolumn{1}{c}{0} & $4 \mathrm{hr}$ & $8 \mathrm{hr}$ & $24 \mathrm{hr}$ & $48 \mathrm{hr}$ \\
\hline T. I. & Diabetes mellitus & 876 & & & 860 & 840 \\
S. M. & Cushing's syndrome & 118 & 128 & 353 & 187 & 177 \\
S. E. & Diabetes Mellitus & 85 & & 82 & 66 & 78 \\
K. S. & Diabetes mellitus & 76 & 100 & 105 & 75 & 34 \\
K. K. & Hypopituitarism & 34 & 41 & 36 & 43 & 42 \\
T. T. & Essential hyperlipemia & 33 & & & & \\
\hline
\end{tabular}

Img of synthetic ACTH was injected intramascularly at 0 time.

limits after the initiation of insulin therapy. The difference between those of responders and of nonresponders to ACTH is not clear at present.

Effect of ACTH on blood cholesterol or phospholipid concentration
Although the effect of ACTH was so apparent in lowering TG concentration, ACTH had no remarkable effect on cholesterol or phospholipid concentration in blood. As shown in Tables 3 and 4 respectively, up to a $48 \mathrm{hr}$ period of observation, no apparent change was observed in all cases.

Table 3. Change in serum total cholesterol concentration $(\mathrm{mg} / \mathrm{dl})$ after ACTH administration

\begin{tabular}{lccccc}
\hline \hline Patient & 0 & $4 \mathrm{hr}$ & $8 \mathrm{hr}$ & $24 \mathrm{hr}$ & $48 \mathrm{hr}$ \\
\hline T. T. & 608 & & & & 630 \\
S. M. & 388 & 369 & 402 & 364 & 314 \\
K. Ta. & & 251 & 287 & 231 & 272 \\
T. I. & 247 & & & 261 & 258 \\
H. A. & & 216 & 194 & 211 & 204 \\
K. K. & 142 & 143 & 138 & 131 & 136 \\
\hline
\end{tabular}

$\operatorname{lmg}$ of synthetic ACTH was injected intramascularly at 0 time.

Table 4. Change in serum phospholipid concentration (mg/dl) after ACTH administration

\begin{tabular}{|c|c|c|c|c|c|}
\hline Patient & 0 & $4 \mathrm{hr}$ & $8 \mathrm{hr}$ & $24 \mathrm{hr}$ & $48 \mathrm{hr}$ \\
\hline Y.S. & 555 & & & 440 & 355 \\
\hline T. T. & 445 & & & & 473 \\
\hline K. Ta. & 350 & 350 & 365 & 305 & 283 \\
\hline S. M. & 338 & 323 & 363 & 313 & 298 \\
\hline T. M. & 323 & & & 358 & 318 \\
\hline T. I. & 310 & & & 318 & 303 \\
\hline Y. I. & 298 & 313 & 288 & & \\
\hline H. A. & & 263 & 205 & 218 & 200 \\
\hline Y. I. & 248 & 245 & 268 & 253 & 245 \\
\hline N. O. & 220 & & 245 & 225 & \\
\hline K. S. & 205 & 235 & 260 & 220 & 208 \\
\hline K. K. & 170 & 178 & 178 & 165 & 175 \\
\hline S. E. & 168 & & 185 & 165 & \\
\hline
\end{tabular}

lmg of synthetic ACTH was injected intramascularly at 0 time. 
Effect of ACTH on blood TG concentration in an Addisonian patient

The TG lowering effect of ACTH was also demonstrated in one patient of Addison's disease due to tuberculosis who had been under the steroid supplement therapy. As demonstrated in Figure 2, his fasting TG concentration in blood was $300 \mathrm{mg} / \mathrm{d} l$ prior to the administration of ACTH. Twenty-four hours after the administration, it decreased to $150 \mathrm{mg} / \mathrm{d} l$ and remained to be lowered in another $24 \mathrm{hr}$ thereafter. Again, no change

\section{T.T. 43 f Addison's Disease}

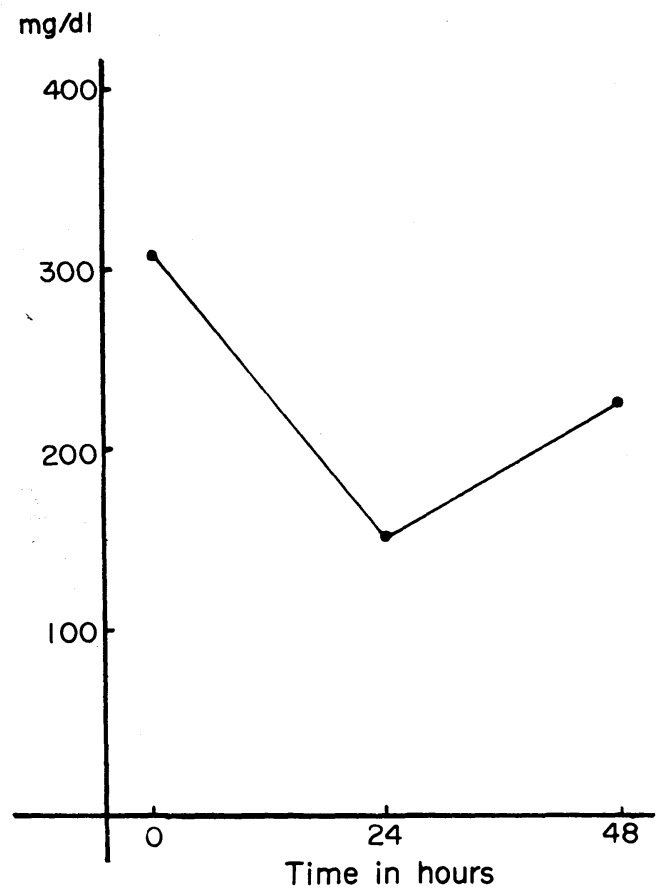

Fig. 2. Change in serum TG concentrations after $1.0 \mathrm{mg}$ ACTH injected intramuscularly.

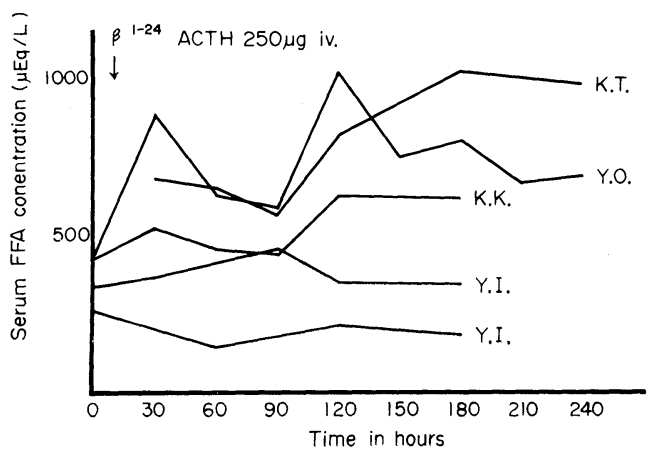

pFig. 3. Change in serum FFA concentration after $\mathrm{ACTH}$ injected intravenously in an amount of $250 \mu \mathrm{g}$.

was observed in his cholesterol or phospholipid concentration by the ACTH administration.

Effect of ACTH on serum free fatty acid (FFA) concentration

ACTH has been known to stimulate lipolysis in adipose tissue when added in vitro or administered in vivo in animals of various species. However, in men no apparent effect on plasma FFA has been observed in vivo. Figure 3 shows the effect of ACTH on the plasma FFA concentration in the patients who responded to ACTH with a decrease of blood TG concentration. No consistent effect on plasma FFA was observed.

Effect of ACTH on posthaparin lipoprotein lipase activity in blood

As shown in Table 5, lipoprotein lipase activity did not change significantly in samples of $4,8,24$ or $48 \mathrm{hr}$ after the ACTH administration in one patient (Y. I.), who showed the

Table 5. Postheparin lipoprotein lipase activity (LLA) after ACTH administration in a patient Y. I.

\begin{tabular}{ccccccc}
\hline \hline Time in hours & 0 & 4 & 8 & 24 & 48 \\
\hline LLA & 0.098 & 0.100 & 0.102 & 0.099 & 0.060 \\
\hline & uEqFFA $/ \mathrm{min} / \mathrm{m} l$
\end{tabular}


marked lowering of blood TG concentration in response to ACTH.

\section{Discussion}

In 1964, Friedman and others reported the hypotriglycedemic effect of ACTH in the literature for the first time (Friedman et al., 1964). They found this effect incidentally while they were studying those hypertriglycedemic subjects exhibiting a particular behavior pattern (type A, according to their designation). Three years later, they reported that ACTH was capable of lowering the fasting and postprandial elevation of plasma TG of the hyperlipemic as well as normolipemic subjects, regardless of their behavior pattern (Friedman et al., 1967). They observed that the injection of $100 \mathrm{U}$ of ACTH prior to the ingestion of the fat meal reduced the average four-hour postprandial plasma triglyceride concentration. They also observed that the depot form of ACTH given $15 \mathrm{hr}$ prior to the fat meal significantly lowered the preprandial and nine-hour postprandial plasma triglyceride levels.

Our results, mostly dealing with fasting plasma TG values, confirm theirs and add some interesting points. Firstly, we have proved that synthetic $\beta^{1-24} \mathrm{ACTH}$ was also effective in lowering the elevated plasma TG level. Friedman et al. excluded the effect of possible contaminants to their ACTH preparations by demonstrating that lipotropin and growth hormone failed to exhibit the effect (Friedman et al., 1967). They also showed the administration of essentially pure ACTH to replicate the effect. Our results clearly show that ACTH per se can serve as a hypotriglycedemic agent in men and also the first 1 to 24 fragment of the peptide is sufficient to exhibit the effect. Secondly, our result shows that the effect of ACTH in lowering plasma TG concentration was so marked, which was not noted in their study. In one patient (Y. I.), the tremendous hypertrigly- cedemia of more than $1000 \mathrm{mg} / \mathrm{d} l$ was decreased to a normal range within $24 \mathrm{hr}$ on one occasion, and almost to a normal limit in $24 \mathrm{hr}$ and to a subnormal range in $48 \mathrm{hr}$ in another. In other patients, marked hyperlipemia was also amended almost completely in $24 \mathrm{hr}$. Thirdly, Friedman et al. failed to demonstrate the hypolipemic effect in Addisonian patients (Friedman et al., 1964). In our patient of Addison's disease, the TG lowering effect was clearly demonstrated by $\mathrm{ACTH}$. The reason for this discrepancy is not clear. However, in spite of their own result, they believed that ACTH itself was active, since a large amount of hydrocortisone did not replicate the effect of ACTH. Finally, the hypotriglycedemic effect of ACTH was apparent as early as $30 \mathrm{~min}$ after its intravenous administration. As for the duration of this effect of ACTH, it was apparent as long as $48 \mathrm{hr}$ and on one occasion lowered plasma TG level remained normal up to $96 \mathrm{hr}$. Most of the study which Friedman et al. reported was up to $24 \mathrm{hr}$ after the ACTH administration (Friedman et al., 1964). They reported that the fasting and four-hour postprandial serum TG values returned to the control level $72 \mathrm{hr}$ after the injection of ACTH (Friedman et al., 1967). They studied the moderately hyperlipemic patients and we also observed a tendency to return toward their previous levels $48 \mathrm{hr}$ after the administration of ACTH in those moderately hyperlipemic patients. The longer effective period we have observed in a patient of marked hyperlipemia may simply be because it takes more time to return to a markedly elevated initial level of plasma TG.

As possible cause(s) for this effect of ACTH, Friedman et al. excluded the participation of insulin which is known to be released by ACTH administration in some species of animals but not in men (Friedman et al., 1967). Insulin pretreatment did not have any effect on pre-and postprandial hypertriglycedemia (Friedman et al., 1967). Serum FFA concentration and postheparin lipoprotein lipase activity was not affected by the ad- 
ministration of ACTH in one patient studied. Thus ACTH seems to have nothing to do with FFA mobilization or TG clearing by lipoprotein lipase. The mechanism of this hypotriglycedemic action still remains to be elucidated. However, judging from its rapid action and prevention of postprandial hyperlipemia, it should be related to the removal of lipid from the blood stream by the liver, probably without the aid of a lipoprotein lipase activity. Judging from the relatively long lived effect, the effect should also be related to the synthesis and release of TG into the circulation from the liver.

As was mentioned in the results, there were some patients who did not respond to ACTH administration despite their elevated plasma TG level. The reason for this discrepancy is not clear at present. Also, further studies are certainly awaited as for the effect of long term administration on plasma lipid concentrations as well as on lipid content in peripheral tissues, especially in liver.

\section{Acknowledgement}

The authors are grateful to Dr. Motoshi Kitamura and the members of the Department of Clinical Biochemistry Laboratory, Toranomon Hospital for measuring the lipid concentration used in this report.

\section{References}

Dole, V. P. (1956). J. Clin. Invest. 35, 150. Frederickson, D. S., K. Ono and L. L. Davis (1962). J. Lipid Res. 4, 24.

Friedman, M., S. O. Byers and R. H. Rosenman (1964). J. Am. Med. Assoc. 190, 959.

Friedman, M., R. H. Rosenman, S. O. Byers and S. Eppstein (1967). J. Clin. Endocrinol. 27, 775.

Henly, A. A. (1957). Analyst. 82, 286.

Kawade, M. (1962). Jap. J. Clin. Med. 20, 2127. (In Japanese)

Shibata, S. and M. Kitamura. NichijoRinsho-Seikagaku-Teiryoho. Nakayama Shoten, Tokyo, p. 137 (1963). (In Japanese) Van Handel, E. and D. B. Zilversmit (1957). J. Lab. Clin. Med. 50, 152.

Yoshida, M. and I. Igarashi (1962). Clin. Pathol. 10, 194. (In Japanese)

Zak, B. (1955). Am. J. Clin. Pathol. 25, 433. 